\title{
UMA PROPOSTA CURRICULAR DE ENSINO MÉDIO À LUZ DE UMA NARRATIVA JUVENIL: LIMITES E POSSIBILIDADES
}

Me. Jean Prette

jean.prette@outlook.com.br

Tutor na Universidade Federal de Santa Catarina

Sandra Michelluzzi Biazotto

sandramichelluzzi@gmail.com

Mestranda pela Universidade da Região de Joinville 
RESUMO: O presente artigo nos direciona a ter um olhar diferenciado acerca de uma proposta curricular, abrindo-nos a um processo crítico/reflexivo referente a perspectiva setorial do Ensino Médio. Toma-se por base a pesquisa desenvolvida por Prette (2017), que discorre um olhar sobre o currículo na perspectiva da 'filosofia da diferença' (GABRIEL, 2013; CORAZZA, 2001), atrelada a narrativa (auto) biográfica de um jovem estudante de Ensino Médio, revelando suas inquietações acerca do limite de se conhecer uma vida e sobre o que fazer com a 'voz do outro' (ARFUCH, 2010). Para compreender os processos de subjetivação de jovens, a pesquisa embasou-se nas obras de Foucault (1999; 2014), como suporte de análise dos discursos que o jovem da pesquisa está atravessado. Evidenciou-se que, ao se dar voz aos jovens inseridos em uma proposta curricular, contribui-se para que os estudantes percebam e analisem o espaço escolar podendo colaborar, também, ao processo de modus operandi organizacional.

PALAVRAS-CHAVE: Currículo, (auto)biografia, subjetivação.

\section{A HIGH SCHOOL CURRICULUM PROPOSAL ENLIGHTED BY A YOUTH NARRATIVE: LIMITS AND POSSIBILITIES}

ABSTRACT: This article directs us to have a distinctive look about a curriculum proposal, opening us to a critical/reflexive process for the high school sector perspective. It takes as a basis the research developed by 'Prette' (2017), which presents a look at the curriculum from the perspective of the 'philosophy of difference' (GABRIEL, 2013; CORAZZA, 2001), linked to the (auto)Biographical narrative of a young high school student, revealing their concerns about the limit to meet a life and about what to do with the 'voice of the other' (ARFUCH, 2010). To understand the processes of subjectivation, the research layed its foundations on the works of Foucault $(1999 ; 2014)$, as a support for the analysis of the speeches that the young student from the research is permeated. It was clear that giving voice to young people inserted in a curriculum proposal, contributes to their realization and analyzes of the school space, as well as enabling cooperation to the process of organizational modus operandi.

KEYWORDS: Curriculum, (auto)biography, subjectivation. 


\section{Introdução}

Este artigo tem por base o pensamento originário da pesquisa de Mestrado em Educação, intitulada: '(Auto)biografia e processos de subjetivação de jovens inseridos na proposta curricular do Ensino Médio’ de um colégio em questão ${ }^{1}$, cujo objetivo era o de 'compreender por meio das narrativas (auto)biográficas pela metodologia da história oral de vida, os processos de subjetivação de jovens do Ensino Médio do Colégio referido'.

De antemão, salientamos como pretensão que as particularidades do currículo, seus processos e ressignificações na perspectiva setorial do Ensino Médio, pode gerar renovações pedagógicas presentes nesta realidade, porém, muitas vezes, não correspondem às expectativas daqueles que estão inseridos nas propostas, ou seja, os jovens estudantes. Para isso, fundamentamos nosso diálogo referente ao currículo com autores da 'filosofia da diferença' (GABRIEL, 2013; CORAZZA, 2001), por evidenciarmos uma perspectiva concreta de caminhar contra a corrente de uma lógica em que se valorizam os conteúdos e não a reflexão, o pensamento, a crítica no processo de formação educacional e humana dos sujeitos, ou seja, os jovens matriculados na proposta curricular.

Ressaltamos assim, que foi um momento de descobertas, de perceber que aqueles que seriam os sujeitos da pesquisa também estão em processo de caminhada, também são atravessados por inúmeras realidades... Jovens estudantes na fase do ensino médio, nível de escolarização que apresenta impasses no sistema de ensino brasileiro e é ainda pouco contemplado pela pesquisa educacional, haja vista que, revisitando os argumentos para se fundamentar a importância da pesquisa, constatou-se existir uma lacuna no conhecimento acerca desse setor.

No itinerário da pesquisa, optamos pela história oral de vida como ferramenta metodológica de coleta das narrativas (auto)biográficas dos jovens estudantes, porém constatamos que enquanto método de coleta não poderíamos avançar na perspectiva das análises. Em vista disso, o questionamento de Arfuch (2010, p. 253) “o que fazer com a voz do outro", ajudou-nos a compreender a importância de analisar, conhecer e compreender... as narrativas (auto)biográficas dos jovens inseridos na pesquisa.

Desse modo, em busca de uma resposta, nos dirigimos ao encontro de Michel Foucault (1999; 2014), que nos levou a entender o que fazer com a voz do outro. Ou seja, o filósofo nos deu suporte para podermos entender os processos de subjetivação dos

\footnotetext{
${ }^{1}$ Os autores optaram por manter sigilo quanto ao nome do Colégio que fora pesquisado.
} 
jovens inseridos na proposta curricular do Colégio em que foi realizada a pesquisa. Em outras palavras, coletamos as narrativas para capturar nelas as subjetividades construídas a partir dos discursos.

\section{O currículo sob a ótica da "Filosofia da diferença"}

Ao iniciarmos esse diálogo, inserindo-nos em um processo de busca constante pelo desconhecido, percebemos que, de modo geral, quando se pensa em escola, automaticamente se presume uma determinada compreensão das propostas curriculares, metodologias, material didático..., em suma, tudo o que vai 'garantir' aos estudantes matriculados na determinada proposta curricular o 'conhecimento/saber' necessário para enfrentar as diversas e diferentes avaliações que serão submetidos ao longo do ano letivo. Por conseguinte, como fundamenta Rose (2001, p. 36-38),

[...] [escolas são] dispositivos de produção de sentidos - grades de visualização, vocabulários, normas e sistemas de julgamento, não são produzidos pela experiência; eles produzem a experiência [...] montagens híbridas de saberes, instrumentos, pessoas, sistemas de julgamento, edifícios e espaços, orientados no nível programático, por certos pressupostos e objetivos sobre os seres humanos.

Além disso, recorda Corazza (2001) que existem sujeitos/pessoas nos currículos..., expectativas de mundos, de eus, de nós:

um currículo é o que dizemos e fazemos... Com ele, por ele, nele. É nosso passado que veio, o presente que é nosso problema e limite, e o futuro que queremos mudado. É a compreensão de nossa temporalidade e espaço. Um "espectro" que remete a todos os nossos outros, e exprime nossa sujeição ao "Outro" da linguagem. Um currículo é a precariedade dos seres multifacéticos e polimorfos que somos. Nossa própria linguagem contemporânea, que constitui uma pletora de "eus" e de "não eus", que falam e são silenciados em um currículo (CORAZZA, 2001, p. 14).

Pensar dessa forma é fortalecer o valor do processo dos jovens estudantes do Ensino Médio, pois são ativos, dinâmicos, buscando respostas para o tempo presente. Levando-se em conta que existem no currículo as intenções adultas, a voz marcante dos corpos docente e dirigente das instituições em relação ao futuro, ao vir a ser, ao desejo de apreensão do já estabelecido, a crença em continuidade, esquece-se a compreensão desse 'jogo temporal da existência', um agora, um presente em que pulsam os anseios dos jovens, um fazer-se como acontecimento do presente, com realidades diversas. Portanto, concordamos e dialogamos com a pesquisa de Venera (2009, p. 64), ao afirmar que "as 
instituições socializadoras, como a família e a escola, enfrentam um desafio diante das iniciativas de desvincular os jovens do sentido de transição".

À vista disso, na contramão do processo sócio-histórico, manifesta-se algo que é imposto como critério fixo, que visa sempre projetar um futuro fixo, estático, formando uma identidade para cada um dos jovens inseridos em determinadas propostas curriculares. Assim, na maioria das vezes o processo escolar está amarrado no discurso de determinadas disciplinas e/ou nos conteúdos aplicados em sala de aula.

Nesse sentido, preferimos, assim como Corazza e Silva (2003, p. 10), “a espiral à seta. $\mathrm{O}$ rizoma à árvore. $\mathrm{A}$ disseminação à polissemia. $\mathrm{A}$ ambiguidade à clareza. $\mathrm{O}$ movimento à forma. A metamorfose à metáfora. $\mathrm{O}$ acontecimento ao conceito. $\mathrm{O}$ impensado ao bom senso". Por conseguinte, conforme a lógica dos processos de subjetivação, Larrosa (1996, p. 37) assegura: “A pessoa humana se fabrica no interior de certos aparatos (pedagógicos, terapêuticos...) de subjetivação". Ante a tal afirmação, questionamo-nos: o que de fato é o currículo? Quais são os conhecimentos que devem ser estabelecidos e considerados como saberes legitimados e não legitimados na base curricular? São questionamentos sobre os quais muitas vezes se reflete, porém eles permanecem sem uma resposta, visto que, como afirma Venera (2009, p. 65),

[...] facilmente o jovem é entendido pela instituição escolar como um sujeito em transição, em formação para o futuro. Alguém que precisa conhecer determinados saberes, construir alguns conceitos, operar certos procedimentos, definir identidades, para o sucesso na fase adulta. Esse presente é difícil de ser considerado.

Se o presente é difícil de ser considerado, é porque muitas vezes as vozes dos jovens são silenciadas pelos muitos conteúdos que são apresentados e impostos a eles como critérios de verdade, por precisarem 'saber'. Com isso, os sujeitos inseridos nas propostas curriculares, precisam passar pelas ressignificações que lhes são apresentadas e acabam sendo aprendizes de saberes preestabelecidos, para serem avaliados em suas 'competências' e 'habilidades'. Não obstante, como diz Gabriel (2013, p. 52):

O conhecimento escolar se reduz à ideia de "conteúdos" que por sua vez são valorizados e legitimados como conhecimentos verdadeiros, e portanto dignos de serem avaliados. Nessa perspectiva, a defesa de uma escola de qualidade, quando não se confunde com a matriz conteudista, não se exime em ensinar os conteúdos disciplinares considerados como poderosos dispositivos tanto emancipatórios como reguladores de uma ordem social desigual. 
Nesse aparato regulador em uma busca constante de conteúdos para fundamentar a credibilidade do currículo estruturado, engessado, as propostas curriculares acabam se tornando uma verdadeira fonte de milagres ao disseminar que o resultado é a garantia de 'excelência', entendido por meio da validação numérica/tabelada que os resultados das avaliações proporcionam.

Mediante a isso, compreendemos que se chegamos a este ponto, é por que no decorrer da história, no tocante da realidade do Ensino Médio, muitas ressignificações aconteceram, e, na expectativa de se encontrar respostas às exigências de cada tempo, novas alternativas eram e são tomadas, ou seja, novas propostas, estruturas, perspectivas visando sempre contemplar o que a sociedade exige. Salientamos isto, porque o foco principal da pesquisa foram os jovens inseridos na proposta curricular do Colégio em questão. Assim, através de suas narrativas (auto)biográficas, percebemos como os mesmos são meros receptores de um sistema que molda e subjetiva cada um no dia a dia da vivência escolar.

Nesta vertente, pensando na atual conjuntura das políticas educacionais em que as escolas estão focadas, ou seja, com maior preocupação na concorrência das estatísticas governamentais, em que se valorizam as notas adquiridas em vista de excelência e resultados duradouros, nos colocamos na iminência de procurar compreender, através do aparato metodológico da história oral de vida, como os jovens se sentem diante de uma certa "pressão" por parte da instituição escolar, família e da sociedade em geral.

Enfim, são pressupostos que nos fazem pensar se realmente existe a necessidade de mudanças tão pesadas no decorrer da história da educação. É claro que as mudanças são necessárias e muito bem vindas, porém, precisam de uma estrutura para que as transformações aconteçam gradativamente, valorizando-se o aspecto vital que é o conhecimento mais abrangente não somente no aspecto científico e formal, mas, pincipalmente, "ouvir a voz do outro/estudante" para auxiliá-lo a entender-se como cidadão e protagonista neste processo de escolarização. Caso não aconteça isso, a escola passará a ser, simplesmente, um lugar onde se vertem conteúdos para corresponder as exigências da sociedade.

Ora, a partir do que foi exposto, frente à realidade contemporânea das propostas curriculares que nos rodeiam, nos reportamos ao objetivo da pesquisa, que foi o de compreender os processos de subjetivação de jovens do ensino médio do Colégio em questão. Assim, o fato de ouvir os jovens já significa um importante passo, mesmo 
sabendo que, como ressalta Delory-Momberger (2016, p. 142) utilizando o pensamento de Ferrarotti (2011), “os seres humanos não são 'dados' que se poderia conhecer a partir do olhar exterior [...] são 'processos em desenvolvimento', seres ancorados no espaço e no tempo, 'sujeitos móveis e incertos"”.

Assim, buscamos como resposta ao questionamento de Arfuch (2010) o pensamento de Foucault $(1999 ; 2014)$ na perspectiva de nos garantir suporte teórico e ferramentas necessárias para trabalhar o conceito dos processos de subjetivação presentes nas narrativas (auto)biográficas dos jovens. Como o filósofo afirma, é através dos,

[...] jogos de verdade [relações de poder no currículo] o homem se dá seu ser próprio a pensar quando se percebe como louco, quando se olha como doente, quando reflete sobre si como ser vivo, ser falante e ser trabalhador, quando ele se julga e se pune enquanto criminoso? Através de quais jogos de verdade o ser humano se reconheceu como homem de desejo? (FOUCAULT, 1984, p. 13, grifo nosso).

Logo, é pertinente pensar que a subjetividade se evidencia pelas relações de poder, que Foucault chama de 'jogos de verdade' (1984). Então, fazer a opção em analisar os relatos (auto)biográficos dos estudantes conforme evidencia o filósofo é afirmar com ele que aceitamos seus questionamentos acerca do 'poder', ou seja, perceber que o currículo evoca uma força na vida daqueles que estão inseridos na determinada proposta. Portanto, com o pensamento do filósofo, percebemos o conceito como um "instrumento de análise capaz de explicar a produção dos saberes" (MACHADO, 1998, p. 10), fortemente evidenciado na narrativa do jovem que veremos a seguir.

Assim sendo, entendemos que os sujeitos da pesquisa estão inseridos em muitas realidades, porém o que aqui destacamos são seus discursos/enunciados no tocante à proposta curricular do Colégio em que estão devidamente matriculados.

Justificamos ainda, que no momento da pesquisa, nos concentramos em coletarmos seis narrativas (auto)biográficas por meio de um roteiro semiestruturado com a base metodológica da história oral de vida. Acolheram-se essas narrativas com atenção criteriosa, tendo em vista as problematizações e os objetivos desta pesquisa. Porém, para este texto, nos concentramos em apresentar uma das narrativas (auto)biográficas, e percebermos assim por intermédio da análise, os processos de subjetivação que fortemente marca a história de vida deste jovem estudante, que muitas vezes, o sistema organizacional escolar, que compreende também a proposta curricular, pensa conhecer, mas na verdade não conhece, pois está preocupada com outros aparatos que darão maior visibilidade à Instituição. 


\section{Um breve relato da (auto)biografia do jovem/estudante Marcos $^{2}$}

Marcos nasceu no dia 22 de fevereiro de 1998 na cidade de Joinville (SC). No dia de nossa conversa tinha 18 anos. Sua gestação era de trigêmeos, porém um bebê faleceu antes de nascer e a outra irmã faleceu ano retrasado, aos 16 anos. O garoto comentou que ela tinha um problema muito sério no coração e que muitas vezes precisou se submeter a exames e cirurgias, mas não soube especificar o porquê, só soube dizer que ela precisou fazer uma cirurgia do coração: "Acho que trocava o tecido que eles usavam pra manter o coração vivo" (2016). Acredita que foi após uma cirurgia no período de recuperação que o corpo não aceitou e ela morreu por "falência total dos órgãos".

Revelou que tinha muito rancor da irmã, pois, como ela precisava de mais cuidados, sempre teve mais atenção. Isso fazia com que ele não tivesse nenhum sentimento por ela, que ela atrapalhava a vida dele. Mesmo ela tendo sérios problemas, ele brigava com ela, não dava atenção nem ajudava a cuidar dela. Mas, depois que ela faleceu, esse pensamento mudou um pouco: "Sinto uma pontada no coração, por não ter dado a atenção, amor a ela, não ter dado o carinho de um irmão, [...] e no dia do velório dela foi o dia que eu mais chorei na minha vida..." (2016). Assim, afirmou que ele não foi o irmão que deveria ser, mas que agora não tem mais como mudar essa situação.

A origem de sua família por parte de pai é alemã. Por parte de mãe, Marcos não sabe ao certo se é alemã ou húngara, mas ressaltou que uma parte é húngara. Contou que uma parte da família era rica e não era esnobe, e a outra, pobre, porém esnobe, afirmando que ostentavam o que não tinham, e o lado da família que era rica não ostentava nada. Explicou que tem contato com os avós, com a avó por parte de mãe e com o avô por parte de pai. Disse que o avô por parte de mãe e a avó por parte de pai faleceram há alguns anos.

Marcos enfatizou que tem muitos problemas com seu pai. Desde sua infância, o garoto não concorda com a criação que seu pai deu para ele nem para sua irmã e que,

\footnotetext{
${ }^{2}$ No decorrer da pesquisa, os jovens foram os narradores de suas histórias de vida. Conforme TCLE assinado pelos responsáveis dos jovens estudantes sujeitos da pesquisa, os nomes foram mantidos em sigilo. Desse modo, no intuito de preservar sua identificação nominal, os nomes aqui colocados foram escolhidos pelos próprios jovens, inspirados na particularidade de cada um.
} 
apesar de seu pai ser batalhador, de ser bem-sucedido na vida, ele não tem orgulho dele e ainda o descreveu como um homem infeliz e fracassado, pois quando era mais jovem praticava um esporte de que gostava muito, mas teve um problema físico e acabou abandonando-o: "Ele é infeliz e por isso que eu considero ele um fracassado, não um fracassado. Fracassado é um termo forte pra usar, mas eu continuo usando ele..." (2016). Quando o assunto é a mãe, ele já encara de outra forma. Consegue descrevê-la como delicada, como uma mulher que é amiga e que está sempre pronta para ajudar. Acredita ter herdado de sua mãe esse lado amigo para com as pessoas.

Sua rotina é dividida entre estudos e trabalho, pois começou a trabalhar na empresa de seu pai dois dias por semana. Acha que a rotina está bem pesada, pois chega em casa cansado e ainda tenta "calibrar" os horários para ter tempo de treinar games, que é sua paixão. Desse modo, salientou que seu maior objetivo é ser um jogador profissional. Disse que, se não conseguir, não precisa ser um jogador, mas que pode ser um “coaching", ou ainda almeja ser dono de uma equipe. No entanto seu maior sonho é estar no mundo dos games, poder crescer e tornar o cenário brasileiro mais visível lá fora. Assim como os games, sua relação com os esportes é muito forte. Gosta de jogos, games, futebol... Basta chamá-lo para qualquer esporte que ele aceita: "Estou sempre pronto para jogar" (2016).

Todavia, justamente por essa paixão pelos esportes enfrenta um problema com o pai, pois este acredita que o menino deva cursar algo que lhe renda dinheiro, porém Marcos não concorda e garante que não vai desistir de seus sonhos.

Em relação aos estudos, contou que estuda, que recorda muito um professor de Filosofia, que ele gostava muito da matéria, pois misturava a matéria com games.

Acaba sofrendo com a rotina, por achá-la muito pesada, e não gosta de pressão, pois não consegue lidar bem com essa situação. Disse que se tiver de lidar com pressão "dá um branco". Contou que não consegue se lembrar de nada. Por esse motivo, quando tem provas, procura nem falar para o pai, pois já sabe a pressão que vai vir dele para tirar notas boas.

Confidenciou ainda que tem depressão e disse sofrer com isso em alguns momentos da vida, mas afirmou ser um "cara" otimista. Porém já pensou em se matar, em desistir de estudar, de fazer as coisas, que já teve anos que tudo desandou na vida dele, que ele perdeu a vontade das coisas, de desistir de tudo. Já quis fazer supletivo para ter mais tempo para se dedicar aos games, pois não encontra motivação no pai: “O meu pai 
tem uma forma estranha de tentar me motivar, que é me desmotivando..." (2016).

No tocante ao futuro, Marcos ressaltou que vai lutar para ser jogador profissional de games, que não vai desistir e que não tem obrigação de ter um futuro, que pode sair do colégio e virar o que ele quiser. Disse que, se quiser sair do ensino médio e se tornar "mendigo", ninguém tem nada a ver com isso, pois ninguém tem nada a ver com a vida dele, mas afirmou que, se assim mesmo alguém falasse algo para ele, ele diria: "Tá! Essa é minha vida e se eu quiser eu viro mendigo..." (2016). Marcos acredita que com o passar dos anos ele está amadurecendo, está mudando para melhor.

\section{Transgressão ou sentido? O que faz sentido?}

A partir da narrativa de Marcos, compreendemos que ao mesmo tempo em que existem assujeitamentos no que diz respeito ao aparato oferecido pela determinada proposta curricular que visa a expertise, destacam-se também diferenças e sentidos.

Por isso, ressaltamos que a narrativa (auto)biográfica de Marcos é singular... Haja vista que, é um jovem marcado desde sua infância por inúmeros acontecimentos. Assim, nas palavras de Deleuze (2006, p. 112-113),

\footnotetext{
[...] se é verdade que o poder investe cada vez mais nossa vida cotidiana, nossa interioridade e individualidade, se ele se faz individualizante, se é verdade que o próprio saber é cada vez mais individualizado, formando hermenêuticas e codificações do sujeito desejante, o que sobra para a nossa subjetividade? Nunca "sobra" nada para o sujeito, pois, a cada vez, ele está por se fazer, como um foco de resistência, segundo a orientação das dobras que subjetivam o saber e recurvam o poder.
}

Inspirado nas palavras do autor, em relação ao pensamento de Foucault no que se refere aos sujeitos na contemporaneidade, e de modo específico para o jovem Marcos, a reflexão resume com maestria algumas das indagações que aqui ressaltamos: enquanto estudantes do colégio em questão, o que dizem esses estudantes sobre eles mesmos, quanto as suas famílias, ao espaço escolar e ao futuro?

Ao ouvir as narrativas de histórias de vida de jovens, de maneira muito concreta, procurando dar ouvidos aos discentes, muitos detalhes particulares do campo familiar e do processo educativo foram elencados. São as singularidades positivas e/ou negativas presentes na vida de todos. No caso específico de Marcos, muito nos chamou a atenção, já que com veemência ele cita sua relação com a família e a realidade escolar. Salienta que desde a sua gestação, que era de trigêmeos - sua mãe perdeu um bebê antes de nascer e a outra irmã, que nasceu com deficiência, veio a falecer aos 16 anos -, gerou nele uma 
realidade de não aceitação muito forte:

\begin{abstract}
sempre fui um irmão muito ruim, muito rude com ela. Até os meus 10, 11 anos eu brigava com ela, batia boca, eu às vezes agredia ela, mais não porque eu não tinha consciência das coisas, e sim porque eu não queria aceitar que ela ganhava mais atenção do que eu. Porque, quando uma criança é criança, ela quer atenção dos pais, ela precisa de atenção dos pais, então muitas vezes eu chegava e mostrava: nossa! Olha, fiz isso; olha, descobri isso, e meus pais às vezes não davam atenção pelo fato dela precisar, tá precisando de uma atenção maior, alguma coisa do gênero. Então desde sempre eu tive um rancor dela, e tanto é que eu falava pra mim que no momento que ela falecesse eu não ia ter, tipo não ia, mostrar meu sentimento. $\mathrm{O}$ maior sentimento que eu poderia demonstrar seria felicidade por eu ter realmente, ter mais ela me atrapalhando. Eu sempre vi ela como um obstáculo [MARCOS, 2016, grifo nosso].
\end{abstract}

Com a afirmação de Marcos, apropriando-nos das fortes expressões de sua narrativa, reportamo-nos a Foucault, que em seu texto "Prefácio à transgressão", afirma: "Em vez de se exprimir, se expõe, vai ao encontro de sua finitude e sob cada palavra vêse remetido a sua própria morte" (FOUCAULT, 2001, p. 46). De fato, por meio da narrativa, da linguagem, Marcos expõe, evidencia em sua trajetória de vida uma "pulsão de morte/dor" imensa. Ou ainda, utilizando o termo foucaultiano, ao narrar, expressa a transgressão dos seus próprios limites, a fragilidade do seu eu, que

desmorona-se sem cessar no centro de seu próprio espaço, deixando a nu, na inércia do êxtase, o sujeito insistente e visível que tentou sustentá-la com dificuldade, e se vê como que rejeitado por ela, esgotado sobre a areia do que ele não pode mais dizer (FOUCAULT, 2001, p. 36).

Assim, concordamos com Leão (2011, p. 99), que se atribui do pensamento de Mellucci (2004) e ressalta: “Os jovens são atores plurais, abertos à experimentação e propensos a assumir diferentes identidades dependendo do contexto e das relações sociais em que estão inseridos". Ao se olhar somente o externo, a realidade de os jovens serem "atores plurais" se concretiza, haja vista que, perante a sociedade em geral, até mesmo aos colegas de colégio, Marcos é um rapaz que vive em um universo de conquistas e facilidades, a ponto de frisar que materialmente não lhe falta absolutamente nada, já que seu pai é "empresário, [...] tem transportadora, tem tecelagem por parte da minha mãe, [...] tem a parte de recapagem de pneus, tem a mecânica de motos, é bem variado, tem bastante coisa, é tudo da família em si. A minha mãe trabalha no financeiro de toda área" (2016).

Perante esse dilema familiar na vida de Marcos, vemos que "há uma ideia consolidada em nossa sociedade da família como responsável única por aquilo que se 
passa na vida dos jovens, especialmente seus 'descaminhos"' (DAYRELL; MOREIRA; STENGEL; 2011, p. 26). Desse modo, destacamos a importância de se conhecer os jovens estudantes, e aqui particularmente Marcos, pois em suas narrativas se tornou muito perceptível o paralelo da angústia referente à família e ao ambiente escolar, porém, para não ficar somente nesse aspecto, o qual desvendaria suas fragilidades, o garoto menciona o aporte econômico, que possibilita uma vida tranquila e serena. Essa realidade torna-se evidente, porque, ao continuar narrando traços peculiares de sua família, ressalta a figura paterna, revelando que o pai é

\begin{abstract}
[...] um empreendedor, ele é muito bom com isso, mas ele não é feliz. Dá pra ver que, apesar dele gostar da empresa, ele não é feliz dirigindo a empresa, ele não é feliz tendo o cargo que ele tem, [...]. Eu digo que, pelo fato dele ter desistido do sonho dele, de estar próximo do que poderia ser o sonho dele, ele é infeliz, e por isso que eu considero ele um fracassado. Não um fracassado... Fracassado é um termo forte pra usar, mas eu continuo usando ele, até porque eu não conheço outro termo que possa ser usado. [...] Pra mim ela não se encaixa, não é uma pessoa que eu quero me espelhar [MARCOS, 2016, grifos nossos].
\end{abstract}

Marcos, pela narrativa citada, enfatiza novamente sua vontade de transgredir, de não seguir os parâmetros normais, que em muitos casos na sociedade seria seguir os desejos dos pais. Tanto que, para Foucault (2001, p. 34),

nada é negativo na transgressão [...]. Mas pode-se dizer que essa afirmação não tem nada de positivo: nenhum conteúdo pode uni-la, pois que, por definição, nenhum limite pode retê-la [...]. Essa filosofia da afirmação não-positiva, isto é, da prova do limite, é ela, creio, que Blanchot definia pelo princípio de contestação. Não se trata ali de uma negação generalizada, mas de uma afirmação que nada afirma: em plena ruptura de transitividade.

Desse modo, sobressai a importância dos jovens de buscarem suas singularidades, pois as relações nas quais estão inseridos estabelecem processos que os engessam, formam uma identidade e fazem com que não sejam eles mesmos. Percebemos na narrativa de Marcos que ele gosta de esportes, como já mencionamos e considera seu pai um fracassado, por ele não ter continuado sua vida de atleta, a ponto de Marcos dizer: "Ele tanto amava, que ele tanto almejava jogar profissionalmente num time famoso, como qualquer criança já sonhou, como qualquer adolescente já sonhou e ele desistiu disso" (2016). Para o garoto, seu pai fez a experiência contrária do sonho, da luta, para se lançar em um "labirinto, não para reencontrá-lo, mas para experimentar [...] a perda dele até o limite, ou seja, até aquela abertura onde seu ser surgiu, mas já perdido, inteiramente espalhado fora de si mesmo, esvaziado de si até o vazio absoluto" (FOUCAULT, 2001, 
p. 39).

Marcos assegura que, pelo fato do pai não ter ido em busca de seus desejos e simplesmente ter obedecido às ordens paternas, hoje obriga o jovem a

[...] fazer coisas que ele não pôde fazer e que ele achou que eu gostei... Ele queria que eu fosse ele, que eu vivesse o que ele não pôde viver, esquecendo do fato que não sou ele. Então, eu quero viver a minha vida, eu quero viver os meus sonhos, não vou desistir deles por nada, nem que eu morra tentando, eu vou morrer tentando realizar o meu sonho [MARCOS, 2016, grifos nossos].

Nessa perspectiva, a transgressão está relacionada a determinados procedimentos que, por intermédio das narrativas, se compreende a ideia não de negação aos acontecimentos por que o jovem passa, mas o de desviar-se, desprender-se, abrir-se ao novo..., não para um limite. Para Foucault (2001, p. 33), essa realidade é evidente:

\begin{abstract}
A transgressão não está [...] para o limite como o negro está para o branco, o proibido para o permitido [...]. Ela está mais ligada a ele [limite] por uma relação em espiral que nenhuma simples infração pode extinguir. Talvez alguma coisa como relâmpago na noite que, desde tempos imemoriais, oferece um ser denso e negro ao que ela nega, o ilumina por dentro e de alto a baixo, deve-lhe entretanto sua viva claridade, sua singularidade dilacerante e ereta. [...] A transgressão não opõe nada a nada [...], ela toma, no âmago do limite, a medida desmesurada da distância que nela se abre e desenha o traço fulgurante que a faz ser.
\end{abstract}

A transgressão provoca, então, essa experiência-limite em espiral. Ou seja, desvela-se em sua insignificância, mas ao mesmo tempo se revela com toda a sua força, como se pode analisar pela narrativa de Marcos (2016):

Pelo fato do meu pai ter desistido de tudo, com relação ao esporte, que eu considero ele como uma pessoa fracassada, eu nunca vou me espelhar nele, até porque hoje em dia ele me obriga a trabalhar na empresa com ele, [...] pra que eu assuma a empresa depois [...]. Eu não vou assumir [...]. Eu não desisto, ele desistiu, então é só por esse motivo, por esse único motivo, por esse grão de areia na vida do meu pai, que nunca vou me espelhar na vida dele. A vida dele não teria que ter sido perfeita, mas ele só não teria que ter desistido.

Diante desse "grito" que ecoa forte..., quantos são os jovens, filhos, estudantes que estão na mesma situação, mas acabam desistindo, com medo de caminhar e de enfrentar a beleza da aventura da vida. Assim, seja na família, seja de modo particular como educadores/pesquisadores, faz-se necessário

reconhecer o jovem existente no aluno, ou seja, as trajetórias juvenis, suas práticas sociais e culturais, sua relação com o mundo do trabalho, com os amigos e com o lazer, dentre outras dimensões, como condição para compreender os sentidos, motivações, atitudes e práticas que desenvolvem na 
sua inserção em processos educativos, que é muito diferente dos jovens alunos das gerações anteriores (DAYRELL; MOREIRA; STENGEL; 2011, p. 15).

Um grande desafio para as gerações anteriores, haja vista que a geração atual se fortalece de meios e condições que até então não faziam ou não fazem parte da geração passada; o que, por ventura, pode ou não auxiliar e/ou prejudicar no sentido do fazer pedagógico e o pensar no próprio currículo escolar.

\section{Considerações finais}

De maneira intrínseca, repensar possibilidades de um currículo mais abrangente no que tange a prática educacional no Ensino Médio, percebe-se a importância de compactuar com a existência da subjetivação em cada ser humano, sobretudo nos jovens estudantes do ensino médio, haja vista que estão em processo de desenvolvimento e a pressão que sofrem passa a ser inexoravelmente tangível nesta fase de vida; isso tudo atrelado ao espaço escolar, vivência familiar e o que a sociedade capitalista dita.

Neste sentido, salientamos que as particularidades do currículo, seus processos e ressignificações na perspectiva setorial do Ensino Médio, muitas vezes não correspondem às expectativas daqueles que estão inseridos nestas propostas, ou seja, os jovens estudantes. Dito isso, ressaltamos a importância de dar "voz" a esses jovens estudantes para descobrir suas ansiedades, angústias, percepções e desejos frente ao presente e seu futuro, pois os sujeitos estão inseridos num contexto histórico social que lhes permitem ou não fazer escolhas ou que, por vezes, os impedem de serem seres singularizados. Podemos perceber isso na narrativa de história de vida de Marcos que salienta ao afirmar que os pais acabam sobrecarregando sua possível singularidade:

Com a superproteção e com super censo de que eu tenho que ser alguém na vida, que eu tenho que ganhar muito dinheiro, que eu tenho que seguir os laços da família, e acabam muitas vezes, virando as costas pro que eu quero pra mim, o que me faz feliz e indo contra minha própria filosofia, que é totalmente contrária da do meu pai [MARCOS, 2016].

Como explicita Foucault (2011, p. 153, grifo nosso), “a penalidade perpétua que atravessa todos os pontos e controla todos os instantes das instituições disciplinares, compara, diferencia, hierarquiza, homogeneíza, exclui. Em uma palavra, ela normaliza".

Desse modo, ao pensar na normalização evidenciada por Foucault, consideramos o conceito de subjetivação nos processos particulares da vida familiar, como também de escolarização, por que Marcos é atravessado. E assim tantos outros estudantes o são.

Portanto, ao se dar voz aos jovens inseridos em uma proposta curricular para que 
expressem seu ponto de vista, expressem sua própria narrativa de vida, contribui-se para que os estudantes percebam e analisem o espaço escolar. Em vista disso, muitas vezes por não se possibilitar que os jovens estudantes falem, como também pela esfera política conteudista visando sempre à qualidade, o modus operandi organizacional acredita-se que os processos educacionais devam ser transmitidos por meio das apostilas/dos livros e que todo o conteúdo seja reproduzido de maneira contundente, por vezes, distanciando o que os jovens estudantes pensam e sentem em relação a si mesmos no tempo presente e futuro.

Contudo, com base nas pesquisas realizadas por Foucault (2011, p. 174), a "escola torna-se [...] um espaço fechado, recortado, vigiado em todos os seus pontos, onde os indivíduos estão inseridos num lugar físico onde os menores movimentos são controlados, onde todos os acontecimentos são registrados".

\section{REFERÊNCIAS}

ARFUCH, L. O espaço biográfico: dilemas da subjetividade contemporânea. Rio de Janeiro: Eduerj, 2010.

CORAZZA, S. M.; SILVA, T. T. Composições. Belo Horizonte: Autêntica, 2003.

CORAZZA, S. O que quer um currículo. Petrópolis: Vozes, 2001.

DAYRELL, J. T.; MOREIRA, M. I. C.; STENGEL M. Juventudes contemporâneas: um mosaico de possibilidades. Belo Horizonte: Editora da PUC Minas, 2011.

DELEUZE, G. Foucault. Tradução de Claudia Sant'Anna Martins. São Paulo: Brasiliense, 2006.

DELORY-MOMBERGER, C. A pesquisa biográfica ou a construção partilhada de um saber do singular. Revista Brasileira de Pesquisa (Auto) Biográfica, Salvador, v. 1, n. 1, p. 133-147, jan./abr. 2016.

FOUCAULT, M.. A hermenêutica do sujeito. Tradução de Márcio Alves da Fonseca e Salma Tannus Muchail. São Paulo: Martins Fontes, 2014.

A ordem do discurso: aula inaugural no Collège de France, pronunciada em 2 de dezembro de 1970. Tradução de Laura F. A. Sampaio. 5. ed. São Paulo: Loyola, 1999.

História da sexualidade 2: o uso dos prazeres. Tradução de Maria Thereza da Costa Albuquerque. Rio de Janeiro: Graal, 1984.

Prefácio à transgressão. In: FOUCAULT, Michel. Ditos e escritos III. Rio de Janeiro: Forense Universitária, 2001. p. 28-46. 
.Vigiar e punir: nascimento da prisão. 39. ed. Petrópolis: Vozes, 2011.

GABRIEL, C. T. Conhecimento científico e currículo: anotações sobre uma articulação impossível e necessária. Teias, v. 14, n. 33, 2013.

LARROSA, J. Literatura, experiência e formação. In: COSTA, Marisa V. (Org.). Caminhos investigativos: novos olhares na pesquisa em educação. Porto Alegre: Mediação, 1996.

LEÃO, G. Entre sonhos e projetos de jovens, a escola... In: DAYRELL, J.; MOREIRA, M. I. C.; STENGEL, M. Juventudes contemporâneas: um mosaico de possibilidades. Belo Horizonte: Editora PUC Minas, 2011.

MACHADO, R. Introdução: por uma genealogia do poder. In: FOUCAULT, Michel. Microfísica do poder. Tradução de Roberto Machado. 13. ed. Rio de Janeiro: Graal, 1998. p. VII-XXIII.

PRETTE, Jean. (Auto)Biografia e processos de subjetivação de jovens inseridos na proposta curricular do Colégio Marista São Luís. 146 f. Dissertação (Mestrado em Educação) - Universidade da Região de Joinville, Joinville, 2017.

ROSE, N. Governando a alma: a formação do eu privado. In: SILVA, Tomaz T. (Org.). Liberdades reguladas: a pedagogia construtivista e outras formas de governo do eu. Petrópolis: Vozes, 2001. p. 30-45.

VENERA, R. A. S. Discursos educacionais na construção das subjetividades cidadãs e implicações no ensino de História: um jazz possível. 327 f. Tese (Doutorado em Educação) - Universidade Estadual de Campinas, Campinas, 2009.

Recebido em: 01/06/2017

Aprovado em: 15/04/2018 